\title{
Dynamic Performance of a Stand-Alone Self-Excited Induction Generator for a Variable Speed Wind Turbine
}

\author{
Dr. M. Lakhsmiswarupa ${ }^{1}$ and. R. Naveena Bhargavi ${ }^{2}$ \\ ${ }^{1}$ Professor, CVR college of Engineering/ EEE Department, Hyderabad, India \\ Email: swarupamalladi@gmail.com \\ ${ }^{2}$ Assoc. Professor, CVR college of Engineering/ EEE Department, Hyderabad, India \\ Email: bhargavi.rn5@gmail.com
}

\begin{abstract}
Induction generators are more appropriate machines for wind energy conversion. Induction generators generally can be operated in two modes i.e. grid or self-excited mode. Among the two, later is of improving importance due to its capability of wind energy conversion (primary) into electrical energy (secondary) for wide range of variations in the operating speed. Poor voltage regulation is observed in machine analysis. Steady-state and transient analysis of selfexcited induction generator surveys that such generators are not efficient enough to maintain the frequency and terminal voltage in the absence of conventional controllers but are only used for stator and rotor currents variations. In this paper modeling of self-excited induction generator for wind energy conversion systems is designed and simulated in MATLAB environment. The system is studied for dynamic period simulation during the starting period, and load variation.
\end{abstract}

Index Terms: Modeling, Dynamic response, Self-Excited Induction Generator, Wind Energy Generation.

\section{INTRODUCTION}

The primary energy sources also known as conventional sources are thermal power generation and nuclear power generation etc. The efficiency of these conventional methods is poor and rather they pollute the environment. Hence, much attentiveness and concentration are necessarily made towards the best usage of nonconventional energy sources such as Wind Energy, Fuel Cell, and Solar Energy etc. Among all of these, Wind Power [4] is economically cheap. Hence nowadays, it is considered as the fastest growing and the most challenging non-conventional energy.

An induction generator is also known as asynchronous generator. Induction generator is an alternating current (AC) generator which works on the principle of induction motor to generate electrical power. Induction generators generally run at speeds above the synchronous speed. Without any internal modifications, a regular AC induction motor can be used as a generator. In applications where high-pressure gas streams to lower pressure, for e.g. Mini hydro power plants and wind turbines usually Induction generators are preferred [13], because simple controls are sufficient in recovering energy.

An induction generator is usually supplied with the required excitation power from an electrical grid. Because of this, induction generators cannot usually "black start" a deenergized distribution system. However, they are often self-excited by using phase-correcting capacitors [14]

To develop the airgap magnetic flux in induction generators, reactive power is required. In case of a standalone system, reactive power is provided by connecting a capacitor bank to the machine. In case of grid connection, reactive power is drawn from the grid to maintain the air gap flux[19, $20 \& 21]$. Frequency and voltage are complex functions of machine parameters for stand-alone systems. Frequency and voltage at the machine will be dictated by the electric grid for a grid tied system, as it is considerably small when compared to the entire system [5].

Due to the ability to produce useful power at various rotor speeds, Induction generators are often used in wind turbines and also in micro hydro installations [8]. Compared to other generators Induction generators are simpler in electrical and mechanical aspects. They do not need any brushes and commutators hence rugged in construction.

An induction generator can operate independently and can generate sufficient reactive power when connected to a capacitor system. The generator will be ceased immediately when the load current of the generator exceeds the capability to supply both load power and reactive power. In such case, the load has to be removed, and the machine has to be restarted either with a DC excitation or with a residual magnetism present in the core. Hence, for wind power generation where speed is always a variable factor, Induction generators are best fit [12]. Induction generators cannot be used alone for grid frequency control as they are load dependent.

Electrical generators which are driven by the wind turbines by using the wind power are mostly used to reproduce electricity [3]. The rotation of blades changes according to the wind direction. These blades as they are connected to the shaft, using the gear box principles, the speed can be improved. The wind Energy is thus converted into electrical energy at the generator and the output of generator will be given to a Step up Transformer $(700 \mathrm{~V} / 33 \mathrm{KV})$. As the speed of wind changes continuously, the energy produced from the wind is also not constant. It varies continuously and gives energy in sudden bursts. About $50 \%$ of the entire energy is given out in just $15 \%$ of the operating time. [1]. The self-excited induction generator (SEIG) is best suited to generate electric power from various nonconventional energy sources [9, 11, \& 13]. 
An induction machine has to be provided with magnetizing energy to be operated as induction generator. A capacitor bank is to be connected across the stator terminals to achieve this [7]. The major problems with the SEIG are as follows: its terminal voltage and frequency are influenced by the prime mover speed, excitation capacitance, load current, and power factor of the load.

The disturbances in the induction motor load and source can be taken care by VSI by injecting the required amount of reactive or active power. The proposed control scheme helps to maintain the rated voltage and frequency of the SEIG.

The output power of the wind turbine can be computed by using the formula given below:

$$
\mathrm{Pw}=0.5 \rho \pi \mathrm{R}^{2} \mathrm{~V}^{3} \mathrm{Cp}(\lambda, \beta)
$$

$\mathrm{PW}=$ Extracted power from the wind

$\rho=$ air density

$\mathrm{R}=$ blade radius (in $\mathrm{m}$ )

$\mathrm{V}=$ wind velocity $(\mathrm{m} / \mathrm{s})$

$\mathrm{Cp}=$ power coefficient

Power coefficient $(\mathrm{Cp})$ is defined as the ratio of the produced output power to the available wind power.

$$
C p=\frac{\text { Fwadturbine }}{\text { wind air }}
$$

$$
\begin{aligned}
& \text { Pwindturbine }=\mathrm{Cp} \times \mathrm{P}_{\mathrm{ax}} \\
& \text { Pwindturbine }=\frac{1}{2} \mathrm{Cp} \rho \mathrm{A} \mathrm{V}^{3}
\end{aligned}
$$

\section{Modeling Of The System}

\section{A. System Configuration}

Figure 1 shows the block diagram of proposed SEIG for wind energy conversion system with the required supply circuit and control method. In SEIG conversion, the power consumption from wind to the electric grid will take place without change in frequency and RMS value of line voltage even with wide range of variations in wind. The proposed model is designed to generate power from the variablefrequency, variable-voltage by using the SEIG [3]. The regulated DC power, which is estimated, is used to charge a battery set and to supply DC loads [6].

Then DC power is estimated and delivered to the DC side of the three-phase voltage source inverter and is to be converted into a three-phase AC power for the AC loads [10] and for the grid connection. An effective and necessary control method is chosen to maintain the terminal dc voltage even with variations in wind turbine speed and with variations in load. Direct vector control strategy involves rotor flux orientation which is highly dynamic in nature. So dynamic performance is much needed for voltage frequency (v/f) control for a grid connected SEIG [12] for both DC and AC power applications. In induction generator, rotor flux is mainly controlled by the direct axis stator current control and quadratic axis stator current control which in turn deliver active stator power [2]. This method is used to control the electrical torque of the SEIG [5] driven by a variable speed wind turbine, where different forms of wind speed variation effect taken into primary consideration. The effectiveness of the scheme is demonstrated through simulation studies by considering different parameters into account.

\section{B. Generator-Side Converter Control}

The generator-side converter is implemented in such a way that the rotor flux and the machine torque both are controlled by field oriented scheme of current control loop. Figure 1 shows the block diagram of SEIG for WECS. The rotor flux can be tuned and controlled by controlling the $d$ axis rotor current with respect to time. The machine torque is independently controlled by q-axis rotor current control [8] [11].

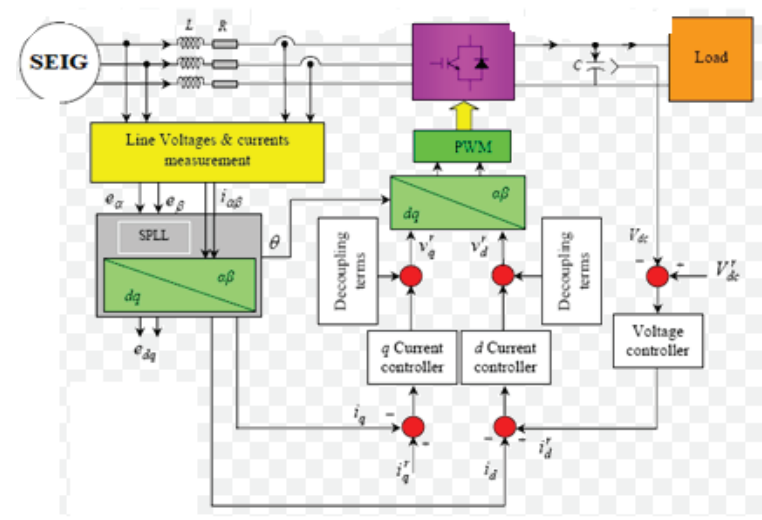

Figure 1. Block diagram of SEIG for WECS

\section{Grid-Side Converter Control}

The grid-side converter control involves two main control methods namely synchronous current control and direct vector control while doing the simulation. Figure 2 shows the entire control scheme of the grid-side converter [15]. The primary aim of the grid-side converter is to keep the $\mathrm{dc}$-link voltage at a constant value without considering the amplitude and direction of the rotor power. The two inner loops involved in the grid side converter control are: inner loop current control through LC filter and control of Dc link voltage through de link voltage control. The SEIG system consists of voltage insertion transformer along with an L-C filter and two PI controllers. LC filter is used to remove high-frequency components from the output voltage of VSC.

This indicates that the dc-link voltage control loop must depend upon the d-component of the grid-filter current. An outer loop DC voltage control is needed to maintain the DC link voltage constant [16]

\section{Control Structure}

The performance of the self-excited induction generator with variable wind speed is studied in three different modes: steady state, transient and dynamic.

The dynamic performance of SEIG is simulated in SIMULINK environment [17] without controllers and its voltage, current, active power and reactive power variation with respect to time is compared with the performance with PID controllers. There are many types of controllers, like: P, I, D, PI, PD, ID PID, controllers.

In Proportional Integral Derivative (PID) controller, only the proportional and integral actions have predominant role of action. The PI controller is advantageous and hence become much popular even when compared to PID 
controller. The steady state error resulting from $\mathrm{P}$ controller can be eliminated using I controller. However, I-controller has drawbacks of slow response and poor overall system stability. Hence I-controller is preferred only when the speed of the response is not an issue of consideration. PI controller cannot reduce the rise time and mitigate the oscillations as PI controller has no ability to predict the future errors of the system. If applied, any amount of current, I, it guarantees certain set point overshoot.

The two methods for varying the parameters of the PID controllers are:

i) Manual Tuning Method: In manual tuning, the parameters are to be monitored and to be adjusted according to the system response. $\mathrm{Ki}, \mathrm{Kp}$ and $\mathrm{Kd}$ are to be changed until the desired system response is obtained by continuous observation of the system response. Example (for no system oscillation): Initially reduce the integral and derivative gains to zero and raise the proportional gain to 100 . Now slowly increase and tune integral value by monitoring the system response. As the system will be settled at some predefined value, that set point has to be modified now to verify whether the system can correct itself within tolerable period of time. If there is no quick response, proceed for lowering the integral value further. Based on the oscillatory behavior of the system, the integral value has to be recorded and to be modified accordingly (say to 100). After increasing the integral gain to 100 , the proportional gain has to be tuned properly such that the oscillations are ceased. Finally, the proportional gain and integral gains are adjusted slowly to get the desired response.

Even though manual tuning method may seems simple, but it is a time consuming process which needs an experience and patience to approach fine tuning. [18]

\section{ii) Ziegler-Nichols Method:}

P-I controllers were popular than PID controllers almost six decades ago. Despite of its faster response and less oscillations, PID controller tends to be unstable even for little variations in the input set point or any disturbances compared to the process of PI Controllers. PID controllers are best recommended by Ziegler-Nichols Method and it is one of the most effective methods.

The basic function of controller is to make the tracking error, $e(t)$ to maintain zero, after reaching a certain phase (wt). Conventional Controllers (PID) [7] mentioned their capability to handle various internal and external disturbances for nonlinear and time varying systems with high accuracy and robustness.

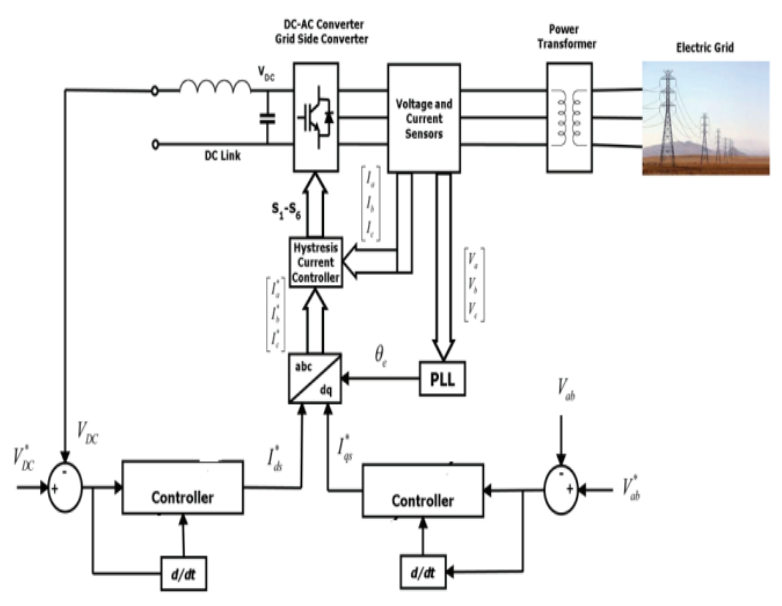

Figure 2. Control scheme of grid-side converter

\section{Simulation Results}

MATLAB stands for Matrix Laboratory. It is a renowned platform to solve various engineering and scientific problems. Earlier, it was a specially designed computer program to compute various matrix operations. Now it has been upgraded into the most efficient computing system which can provide solutions to many technical problems in various fields of engineering.

MATLAB possess a huge library of many predefined functions and toolboxes to make scientific programming tasks simpler and can provide more efficient solutions. It is an extensive program, with an incredibly rich variety of functions. It also has a versatile built-in function for data analysis and various tool boxes provide versatile function capability in different specializations. A performance analysis of wind-powered self-excited induction generator (SEIG) is modeled using MATLAB Simulink. The main origin of difficulties mentioned in the control of the proposed design is nonlinear in nature.

To meet the required time domain specifications for eg. Minimum overshoot, less settling time and low steady-state error, the PID current controllers (in $\mathrm{d}$-q reference frame) are designed and analyzed.

Based on the dynamics of the DC link, the specifications of the inner loop voltage control are accomplished by proper design of PI voltage controller. The main merits [2] of the proposed system are: (1) Extensive control over active and reactive powers near the DC -bus (2) Unity power factor operation (3) Economically full utilization (3) disturbances due to load can be neglected and voltage compensation can also be done. 
The dynamic performance of the proposed system is tested by simulating the model using MATLAB Simulink. The results were analyzed for stator and rotor reference frame. The simulation model is shown in Figure 3 and the results were shown in Figures 4-8 and are summarized in Table I.

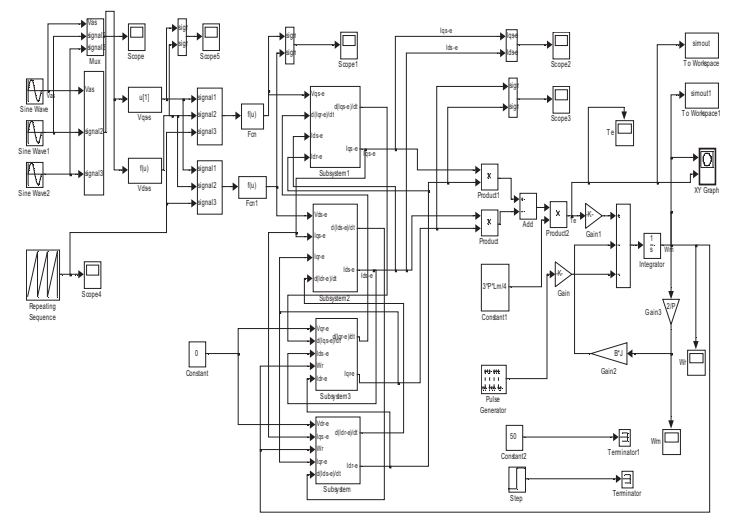

Figure 3. Simulation model of Self-excited induction generator for WECS (With PI controller)

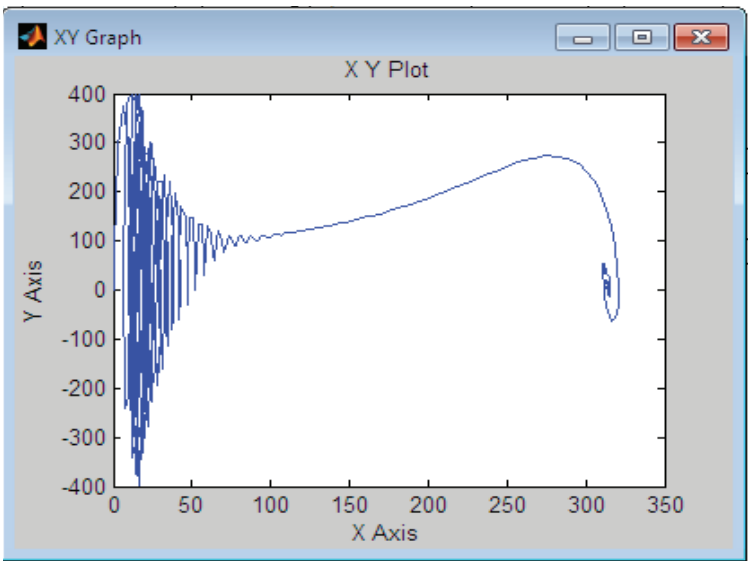

Figure 4. Speed (rpm) versus torque plot

Figure 4 shows speed versus torque plot. Speed-Torque X-Y plot is obtained in plotter for dynamic changes in load with respect to time. Here Speed variation is observed with the changes in the load torque.

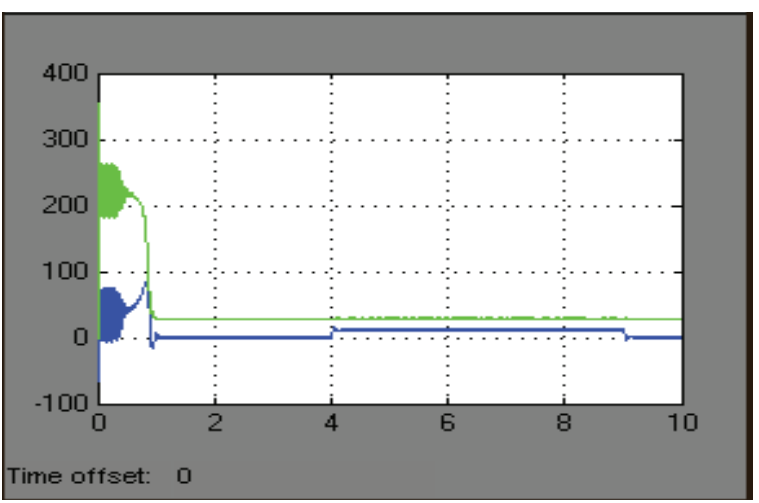

Figure 5. Stator quadrature and direct currents (Amps) versus time (secs)
Using Park transformation, the three-phase quantities are transformed to $\mathrm{dq}$ reference frame. Variation of Stator quadrature axis and direct axis currents with the dynamic changes in load with respect to time are shown in Fig.5.

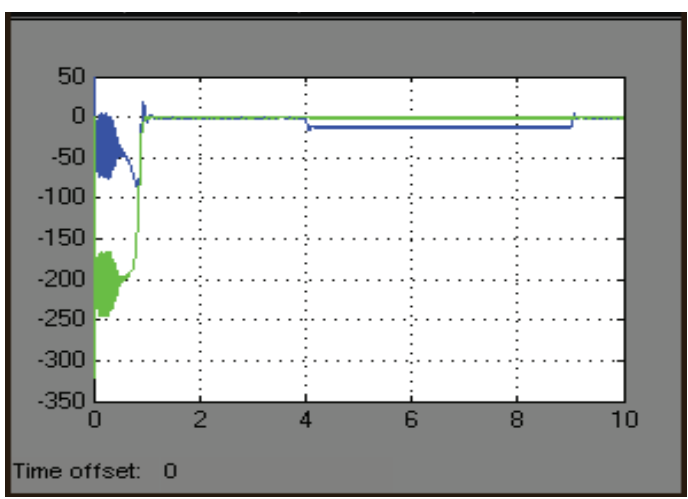

Figure 6. Rotor quadrature and direct currents (Amps) versus time (secs)

Rotor quadrature and direct currents are varied with the dynamic changes in load with respect to time and shown in Figure 6.

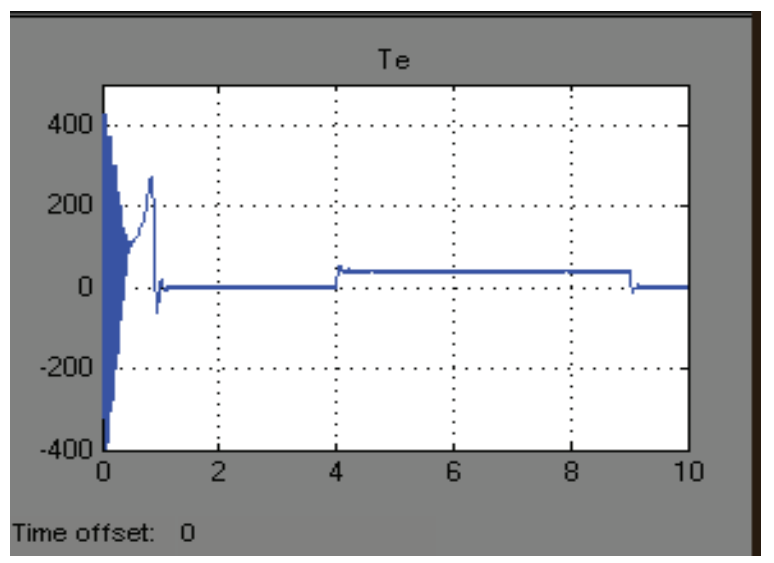

Figure 7. Electromagnetic torque (N-m) versus time (secs)

From Figure 7, Electromagnetic torque $(\mathrm{N}-\mathrm{m})$ variation is observed with the changes in the load torque for dynamic changes in load with respect to time.

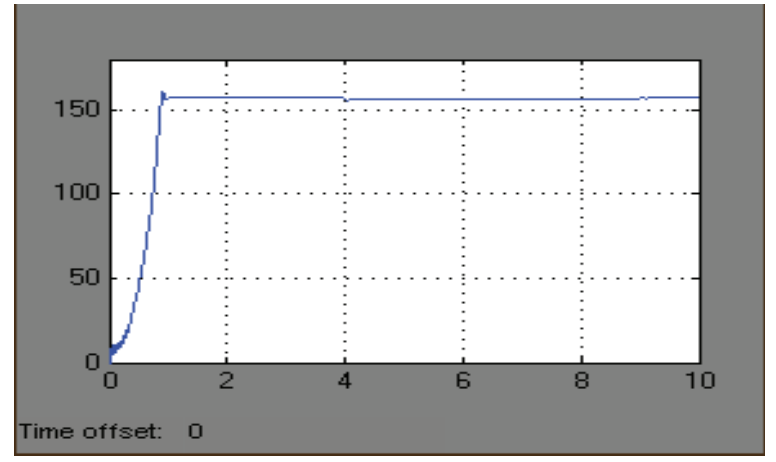

Figure 8. Speed (rpm) versus time (secs)

Figure 8 shows Variation in Speed (rpm) with the changes in the load torque for dynamic changes in load with respect to time. 


\section{CONCLUSIONS}

Simulation analysis of wind energy driven SEIG which supplies power to the utility grid is being presented in this paper. The controller parameters are tuned according to the tracking error by using Zeigler-Nicolas method.

TABLE I.

DYNAMIC RESPONSE OF SELF-EXCITED INDUCTION GENERATOR

\begin{tabular}{|c|c|c|c|c|c|}
\hline & & \multicolumn{2}{|c|}{ Amplitude } & \multicolumn{2}{|c|}{ Time(secs) } \\
\hline & & $\begin{array}{l}\text { Without } \\
\text { Controller }\end{array}$ & $\begin{array}{l}\text { With PID } \\
\text { Controller }\end{array}$ & $\begin{array}{l}\text { Without } \\
\text { Controller }\end{array}$ & $\begin{array}{l}\text { With PID } \\
\text { Controller }\end{array}$ \\
\hline \multirow[t]{2}{*}{ Stator } & Quadrature & 90 & 70 & \multirow{2}{*}{$\begin{array}{l}\text { Obtained } \\
\text { at }(1.2- \\
1.8) \text { secs }\end{array}$} & \multirow{2}{*}{$\begin{array}{l}\text { Obtained } \\
\text { at }(0.8-1) \\
\text { secs }\end{array}$} \\
\hline & Direct & -116 & -100 & & \\
\hline \multirow[t]{2}{*}{ Rotor } & Quadrature & 65 & 50 & & \\
\hline & Direct & -10 & -200 & & \\
\hline
\end{tabular}

The PID parameters considered in simulation are $\mathrm{K}_{\mathrm{p}}=5$, $\mathrm{K}_{\mathrm{i}}=0.2$ and $\mathrm{K}_{\mathrm{d}}=2$. The estimation of the dc link voltage to control the SEIG is done by which the desired performance of the power converter and the inverter is being achieved. Simulation studies are carried out with PID controller and the obtained results are compared with the proposed optimal tuned controller.

The simulation results verified the effectiveness and robustness of the proposed tuning technique. The results were verified with respect to the transient behavior of the wind energy system for different operating conditions. This work can be extended further by using Fuzzy Logic Controller (FLC), Artificial Neural Network (ANN) and Particle Swarm Optimization (PSO) controller which can provide a reactive power control and serve as shunt active power filter as well as a wind energy extractor.

\section{REFERENCES}

[1] H. Geng, D. Xu, B.Wu and W.Huang, "Direct Voltage Control for a Stand-Alone Wind-Driven Self-Excited Induction Generator with Improved Power Quality". IEEE Transactions on Power Electronics, No.26, pp.2358-2368, 2011

[2] D. Seyoum, M.F. Rahman, and C. Grantham, "Terminal Voltage Control of a Wind Turbine Driven Isolated Induction Generator Using Stator Oriented Field Control". Proceedings of IEEE Power Electronics Conference and ExpositionAPEC, No.2, pp. 846-852, 2003.

[3] S. S. Murthy, O. P. Malik, and A.K. Tandon, "Analysis of self-excited induction generators," Proc. IEE, vol. 129, No. 6, pp. 260-265, 1982.

[4] G. Raina and O. P. Malik, "Wind energy conversion using a self-excited induction generator," IEEE Transactions on. Power Apparatus and Systems, vol. PAS-102, no.12, pp.39333936, 1983.

[5] F.M.Fayez, El-Sousy, Mohamed Orabi and Hatem Godah: "Maximum Power Point Tracking Control Scheme for Grid Connected Variable Speed Wind Driven Self-Excited Induction Generator", The Korean Institute of Power Electronics (KIPE), Journal of Power Electronics (JPE), Vol. 6, No.1, pp.52-66, January 2006.
[6] Lahcene Quazene and George McPherson: "Analysis of The Isolated Induction Generator", IEEE Trans. on Power Apparatus and Systems, Vol.PAS-102, No.8, pp.2793-2798, August 1983.

[7] R. Cárdenas, R. Peña, G. Asher, and J. Clare: "Control strategies for enhanced power smoothing in wind energy systems using a flywheel driven by a vector-controlled induction machine", IEEE Trans. Ind. Electron., vol. 48, pp. 625-635, June 2001.

[8] C. Seyoum, Grantham and M. F. Rahman: A novel analysis and modeling of an isolated self-excited induction generator taking iron loss into account, IEEE Transactions on Industrial Applications Vol. 35, No. 3, April 2003.

[9] M. Godoy Simoes, Felix A. Farrett," Alternative energy systems: design and analysis with induction generators", CRC Press, Taylor \& Francis Group, Boca Raton London, New York 2008.

[10] Shakuntla Boora, "Analysis of Self-Excited Induction Generator under Balanced or Unbalanced Conditions", ACEEE International Journal on Electrical and Power Engineering, Vol. 01, Issue No. 03, December 2010.

[11] Shakuntala Boora, Gitanjali Das, "Simulink Modeling of Induction Machine Performance in Different Reference Frames", International Journal of Electronics, Electrical and Computational System IJEECS ISSN 2348-117X Volume 5, Issue 4 April 2016.

[12] H. Geng. D. Xu and B. Wuare, "Direct voltage control for a stand-alone wind-driven self-excited induction generator with improved power quality," IEEE Trans. on Power Elect., vol. 26, no. 8, pp. 632-641, August 2011.

[13] A. Karthikeyan, C. Nagamani, G. Saravana, A. Sreenivasulu, "Hybrid, open-loop excitation system for a wind turbine driven stand-alone induction generator" IET Journal on Renewable Power Generation, vol. 5, Issue no. 2, pp.184-193, August 2011.

[14] T. Burton, D. Sharpe, N. Jenkins, and E. Bossanyi, Wind Energy Handbook, John Wiley \& Sons Ltd., Chichester, England, 2001.

[15] B. Singh and L. B. Shilpakar, "Analysis of a novel solid state voltage regulator for a self -excited induction generator", IEEE Proceedings on Generation, Transmission and, Distribution, vol. 145, no. 6, pp. 647-655, November 1998.

[16] N.S.Jayalakshmi and D.N.Gaonkar, 'Dynamic Modeling and Analysis of an Isolated self-excited induction generator driven by wind turbine", IEEE Transsactions, pp. 1-5,2012.

[17] Avinash Kishore, G.Satish Kumar, "A Generalized StateSpace Modeling of Three Phase Self-Excited Induction Generator For Dynamic Characteristics and Analysis", IEEE Trans.at.ICIEA 2006.

[18] Birendra Kumar Debta, Kanungo Mohanty “Analysis, Voltage Control and Experiments on a Self-Excited Induction Generator". Vol..9, Journal on Renewable Energy \& Power Quali

[19] K. Trinadha, A. Kumar, K. S. Sandhu, "Study of Wind Turbine based SEIG under Balanced/Unbalanced Loads and Excitation' 'International Journal of Electrical and Computer Engineering (IJECE) Vol.2, No.3, pp. 353-370, , June 2012.

[20] A. Kishore, R. C. Prasad, and B. M. Karan, 'MATLAB SIMULINK Based DQ Modeling and Dynamic Characteristics of Three Phase Self Excited Induction Generator', Progress In Electromagnetics Research Symposium, Cambridge, USA, pp. 26-29, March,2006.

[21] D. Seyoum, C. Grantham, and M.F. Rahman, "The dynamic characteristics of an isolated generator driven by a wind turbine," IEEE Trans. on Ind. Appl., vol. 39, no.4, pp. 936944. July/ August 2003. 